\title{
Synthesis, Characterization and Textural Analysis of Functionalized Mesoporous Silica Using Sodium Silicate as Precursor and Silicone Surfactant as Template
}

\author{
Sameer H. Kareem* Inaam H. Ali* Moayed G. Jalhoom**
}

Received 20, December, 2012

Accepted 5, February, 2014

\begin{abstract}
:
Three mesoporous silica with different functional group were prepared by one-step synthesis based on the simultaneous hydrolysis and condensation of sodium silicate with organo - silane in the presence of template surfactant polydimethylsiloxane polyethyleneoxide (PDMS - PEO). The prepared materials were characterized by Fourier transform infrared spectroscopy (FTIR), thermogravimetric analysis (TGA), atomic force microscopy (AFM) and nitrogen adsorption/desorption experiments. The results indicate that the preparation of methyl and phenyl functionalized silica were successful and the mass of methyl and phenyl groups bonded to the silica structure are $15,38 \mathrm{mmol}$ per gram silica. The average diameter of the silica particles are 103.51, 167.25 , and $86.41 \mathrm{~nm}$ while the average pore diameter are 6.7, 16.4, and $2.7 \mathrm{~nm}$ for unfunctionalized, methyl, and phenyl functionalized silica respectively.
\end{abstract}

Key words; mesoporous silica, functionalized silica, silicone surfactants, texture analysis, pore diameter

\section{Introduction:}

The development of porous materials with large specific surface area is currently an area of extensive research, particularly with regard to potential applications in area such as adsorption[1], in packing columns for chromatography[2], catalysis[3], sensors technology, and gas storage [4].

The most important families of these materials are MCM (acronym of Mobil Crystalline Materials) and SBA (acronym of Santa Barbara type Amorphous Materials). These materials are the most used materials and may have different internal pore size, depending on the surfactant and synthesis conditions $[6,7]$.

The use of sodium silicate as a precursor in the synthesis of porous silica has recently increased in modern materials science because it is a low-

cost silica source. Some studies have proved that it is possible to prepare mesoporous silica from sodium silicate solution by precipitation, using nonionic surfactants and triblock copolymer as templates[8]. In addition, there are a few reports concerning the synthesis of mesoporous silica from inorganic silicate sources using nonionic surfactants as templates. For example Das et al. prepared spherical mesoporous silica from sodium silicate, using CTAB as a surfactant and propanol as a cosurfacant, the synthesis proceeded over 3 days under heating condition, and the pore size distribution of mesoporous silica was broad [9]. Naik et al. synthesized mesoporous silica fibers and discoids endowed with circular pore architecture, using disodium trioxosilicate and cetyltrimethyl-

*Chemistry Department / College of Science for Women/Baghdad University

**Ibn Sine Science Company / Ministry of Industry 
ammonium chloride (CTAC) as the silica source and surfactant, respectively [10]. Wei et al. reported that MCM-48 can be prepared by using industrial fumed silica and mixed surfactants of CTAB and Triton X-100 [11].

Surface-functionalized mesoporous materials with various active sites have been extensively investigated in recent years because functional modification permits tailoring of the surface properties for numerous potential applications in the fields of heterogeneous catalysis and adsorption-separation. Generally, the modification of mesoporous materials typically employs two approaches: (1) a silane containing the desired functional group is added to the synthesis mixture and the functional group is incorporated during synthesis, and (2) in which the functional group is incorporated after the surfactant/polymer template is removed from the mesopores[12].

Organic functional mesoporous materials are one of the most exciting new developments in nanotechnology and materials science in the last decade $[13,14]$. Several papers have reported the modification of aliphatic hydrocarbon [15], thiol [16,17], sulfonic ligand [18,19], phenyl [20] within the small pore silica such as MCM and SBA through multistep or direct synthesis method.

It expanded the utility of this type materials in chemistry, physics and materials science, the phenylfunctional mesoporous silica materials can be used as adsorption materials in separation such as solid phase microextraction coupled with highperformance liquid chromatography [21,22].

In this study, functionalized porous silica was synthesized as typical ordered porous silica, and the organosilane functionalization was performed by one-step synthesis based on the simultaneous hydrolysis and condensation of sodium silicate with organo-silane in the presence of template surfactant polydimethylsiloxane-

polyethelyneoxide (PDMS-PEO). To our knowledge, this paper is the first report of using (PDMS-PEO) as a template to synthesize functionalized porous silica. Phenyltriethoxysilane (PTES) and methyltriethoxysilane (MTES) were used for functionalization. The functionalized silica has been characterized by Fourier Transform Infrared Spectroscopy (FT-IR), Atomic Force Microscopy (AFM), and Thermal Gravimetric Analysis (TG).

\section{Materials and Methods:}

\section{Materials:}

Aqueous solution of Sodium silicate $\left(14 \% \mathrm{NaOH}, 27 \% \mathrm{SiO}_{2}\right)$ as a source of silica and the surfactant (polydimethylsiloxane-

polyethyleneoxide PDMS-PEO) as a copolymer were purchase from locally market. Methyltrichlorosilane (MTCS) and phenyltrichloroslane (PTCS) were purchased from Flucka AG. Hydrochloric acid and absolute ethanol were purchased from BDH.

\section{Characterization}

There are many techniques have been used in the characterization of the silica prepared, these are:

- The IR spectra of silica samples were recorded over the range of 4000$500 \mathrm{~cm}^{-1}$ by means of Fourier transform infrared spectroscopy (FTIR), using FTIR spectrometer SHIMADZU.

- The particle size and particle size distributions were analyzed using Atomic Force Microscopy(AFM) SPM-AA 3000, Advanced Angestrum Inc., USA. 
- Thermogravimetric analysis (TGA) was performed using PerkinElmer TGA 4000 instrument, from $30.00 \mathrm{C}$ to $900.00 \mathrm{C}$ at a heating rate $20.00 \mathrm{C} / \mathrm{min}$ using helium as inert gas.

The texture analysis of the surfaces areas were determined from $\mathrm{N}_{2}$ adsorption-desorption isotherm at $77 \mathrm{~K}$ with Micrometrics ASAP 2020 V3.04G analyzer (micromeritics, Inc., USA )

\section{Synthesis}

- The preparation of methyltriethoxysilane (MTES) and phenylrtiethoxysilane (PTES) were carried out by reaction of a stiochoimetric amount of MTCS and PTCS respectively with absolute ethanol.

- The preparation of inorganic and organic functionalized silica was performed following a procedure modified from that initially developed by Huo and Margolese [23]: $1 \mathrm{~g}$ of (PDMS-PEO) was dissolved in $25 \mathrm{ml}$ of deionized water, in a $250 \mathrm{ml}$ beaker $1 \mathrm{~g}$ of sodium silicate was dissolved in $20 \mathrm{ml}$ of deionized water or a mixture of $6 \mathrm{ml}$ of MTES or $6 \mathrm{ml}$ of PTES were added to this solution. Finally $15 \mathrm{ml}$ of $36 \% \mathrm{HCl}$ were also added to the resulting mixture. The obtained solid products were recovered by filtration, washed and dried at $373 \mathrm{~K}$. The surfactant was removed by stirring $1 \mathrm{~g}$ of the dried sample with a solution of $5 \mathrm{ml}$ of $\mathrm{HCl}(36 \%)$ in a $150 \mathrm{ml}$ of ethanol at $333 \mathrm{~K}$ for 1 hour. The quantitative removal of the surfactant required in general two consecutive extractions.

\section{Results and Discussion}

The acid catalyzed sol-gel reactions (hydrolysis and condensation) of sodium silicate and a mixture of sodium silicate and organosilane $\mathrm{RSi}(\mathrm{OEt})_{3}$ ( $\mathrm{R}$ is methyl or phenyl) is illustrated in scheme -1 .

\section{Hydrolysis}
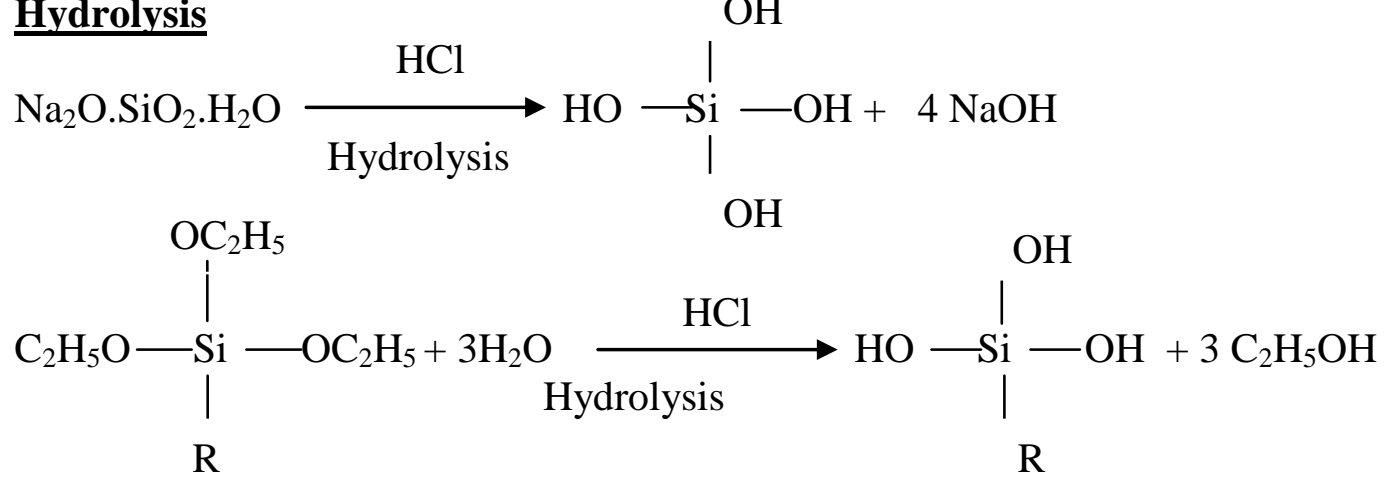

( $\mathrm{R}=$ methyl or phenyl group)

\section{$\underline{\text { Co-condensation }}$}

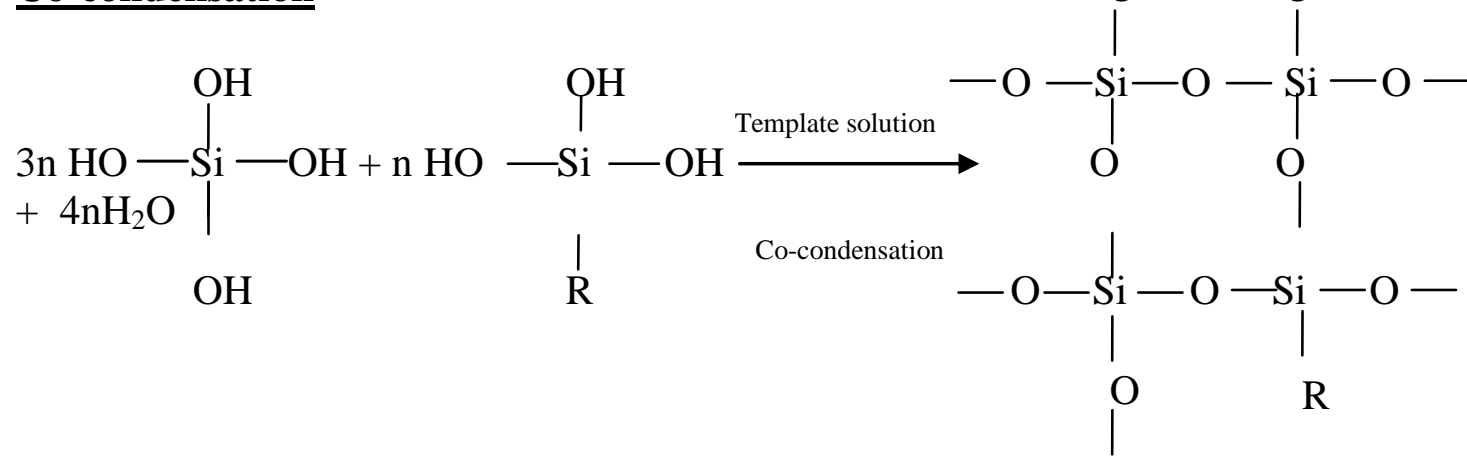

Scheme -1: the sol-gel reaction of the sodium silicate and $\mathrm{RSi}\left(\mathrm{OC}_{2} \mathrm{H}_{5}\right)_{3}(\mathrm{R}$ is methyl or phenyl). 
It is known that the hydrolysis rate increase with substituent that reduce the steric crowding around silicon, so the hydrolysis rate of sodium silicate is relatively faster than that of organically modified silane and the sol-gel reaction proceed in stepwise, i.e. sodium silicate is hydrolyzed and condensed first to form the silica matrix whereas the MTES and PTES units subsequently hydrolyze and cocondense on the pre-formed silica network surfaces which suggest that the organic groups are located on the inner surface of the silica matrix.

The silica were characterized by FTIR spectroscopy between 4000 and 500 $\mathrm{cm}^{-1}$ and represented in Figure (1). The absorption bands observed at around

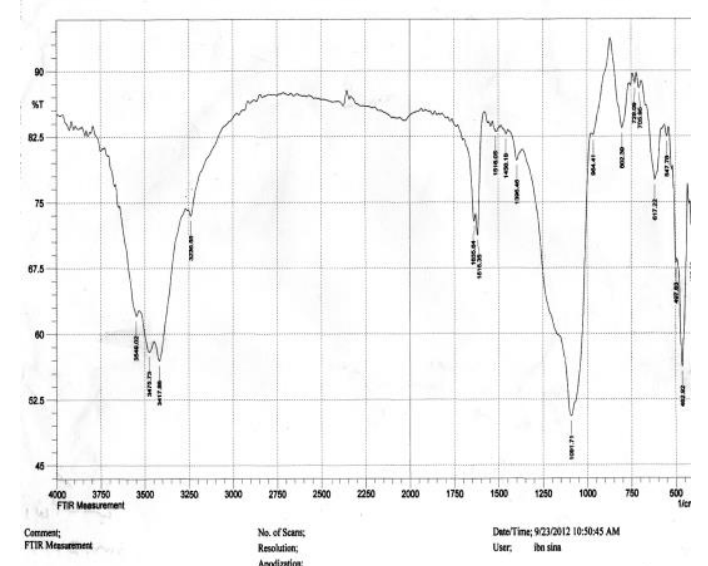

A
$3437 \mathrm{~cm}^{-1}$ and $929 \mathrm{~cm}^{-1}$ indicate the presence of water and $-\mathrm{OH}$ groups. The intensities of these bands are decreased in the samples of silica functionalized with methyl and phenyl groups which indicate the hydrophobic behavior of the functionalized silica. Also, the vibration of the Si-O-Si bond is represented by the absorption band at $1090 \mathrm{~cm}^{-1}$ which are strong in all samples.

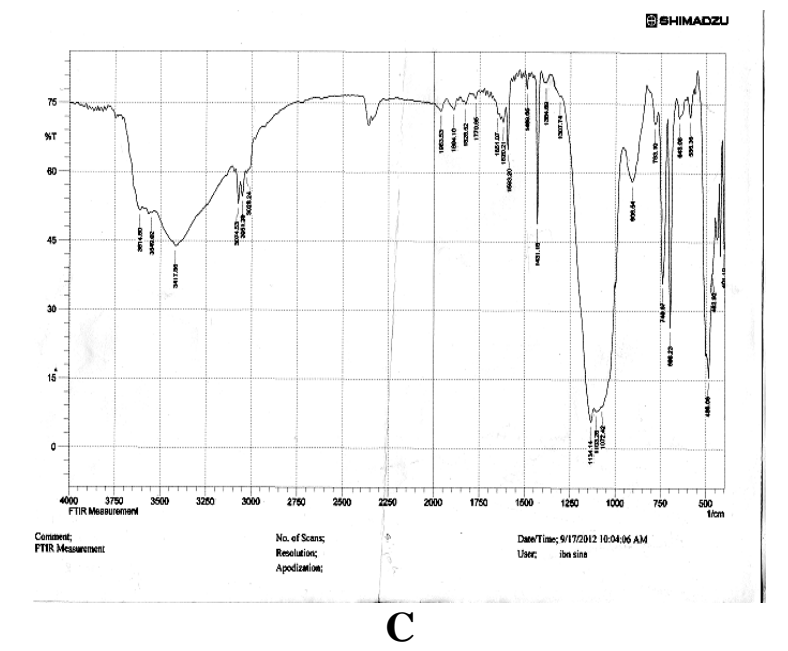

Fig. (1): FTIR spectra of (a) Silica

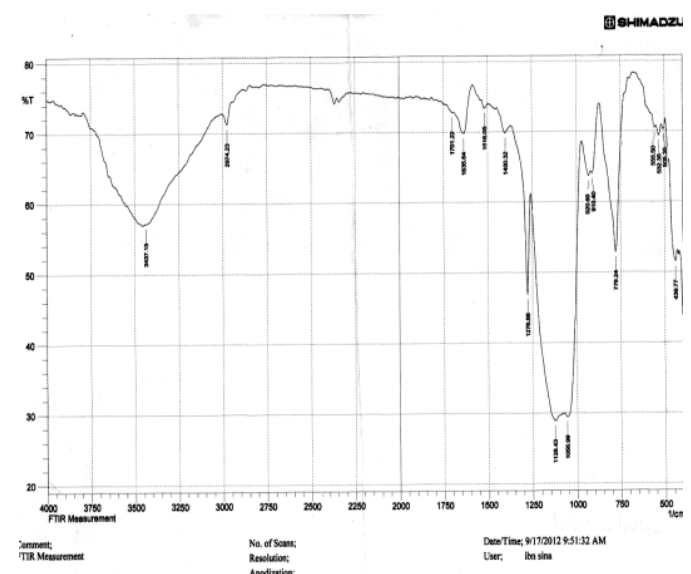

B

(b) Methyl Functionalized Silica

(c) Phenyl Functionalized Silica 
The main features of the spectra of silica functionalized by methyl group were the characteristic band for aliphatic $\mathrm{C}-\mathrm{H}$ stretching vibration of methyl group at around 3000-2800 $\mathrm{cm}^{-1}$, and the strong sharp band at 1276 $\mathrm{cm}^{-1}$, characteristic of the symmetric bending mode of the methyl group in methylsilanes. These results provide evidence that the preparation of methyl functionalized silica was successful.

The absorption peaks of phenyl group are observed at which associated with the stretching vibration of ring $\mathrm{C}-\mathrm{H}$ and out-of-plane bending of $\mathrm{C}-\mathrm{H}$ bonds are clearly identifiable at $1431 \mathrm{~cm}^{-1}$, $698 \mathrm{~cm}^{-1}$ and $740 \mathrm{~cm}^{-1}$ respectively.

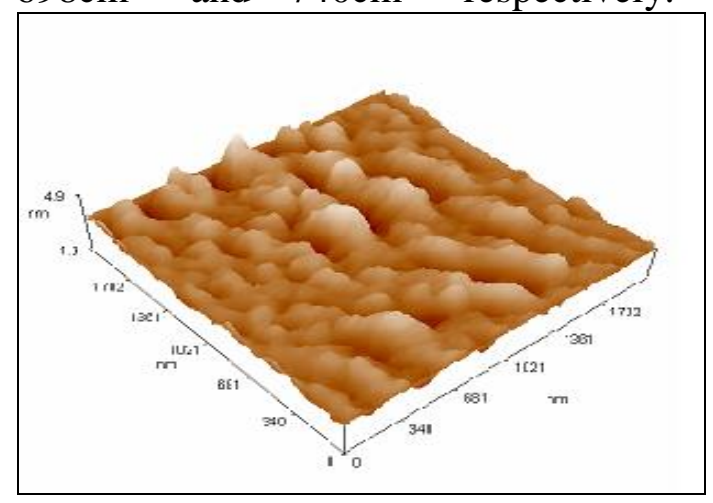

Also, the appearance of an additional peak at $3074 \mathrm{~cm}^{-1}$ indicates the presence of aromatic $\mathrm{C}-\mathrm{H}$ bonds. This suggesting that the phenyl groups have been incorporated into the silicate network.

The AFM pictures (in two and three-dimensional) and granularity distribution charts for the three silicas prepared were represented in Figures ( 2-4 ). It show that the diameter of the particles in the range $30-250 \mathrm{~nm}$ and the average particle size were 103..51, 167.25 and $86.41 \mathrm{~nm}$ for unfunctionalized, methyl and phenyl functionalized silica respectively.

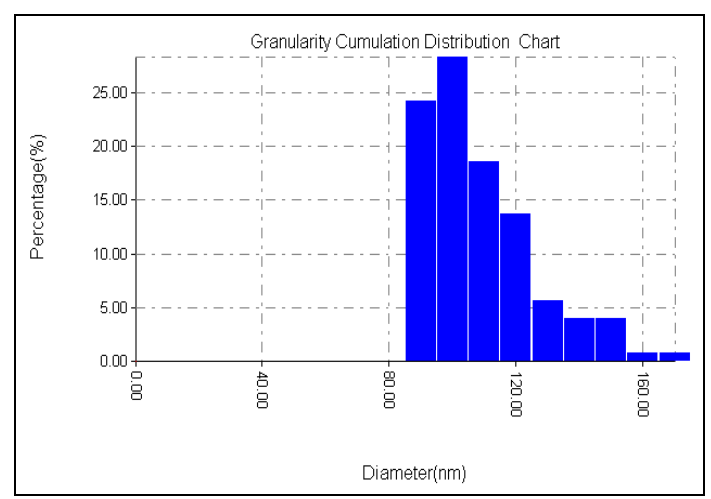

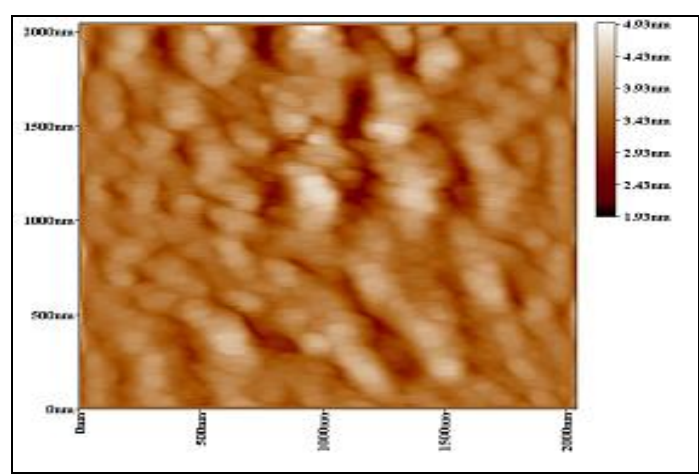

Fig.(2) AF M picture and grain size distribution of unfunctionalized silica 

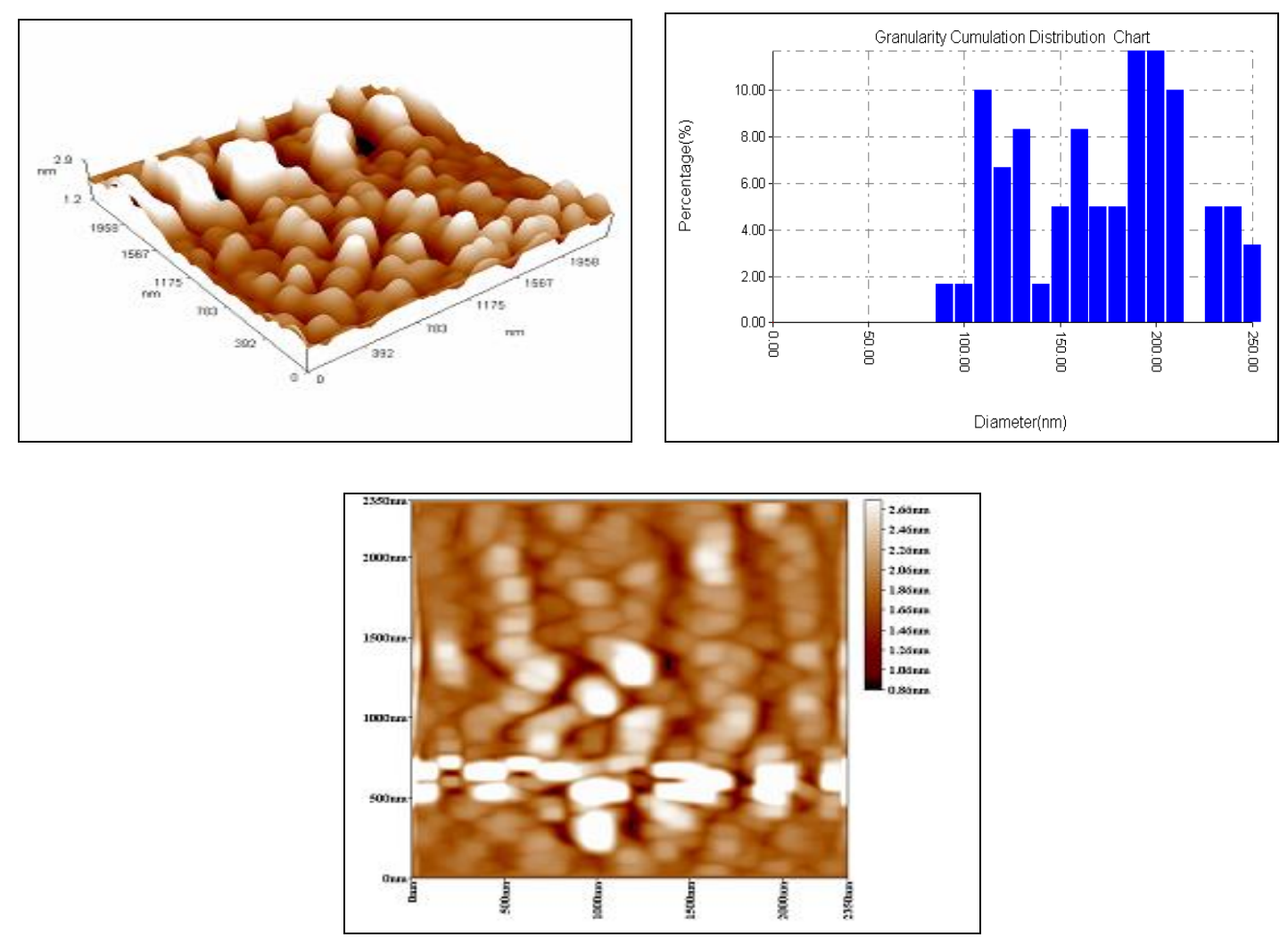

Fig. (3): AFM picture and grain size distribution of methyl functionalized silica
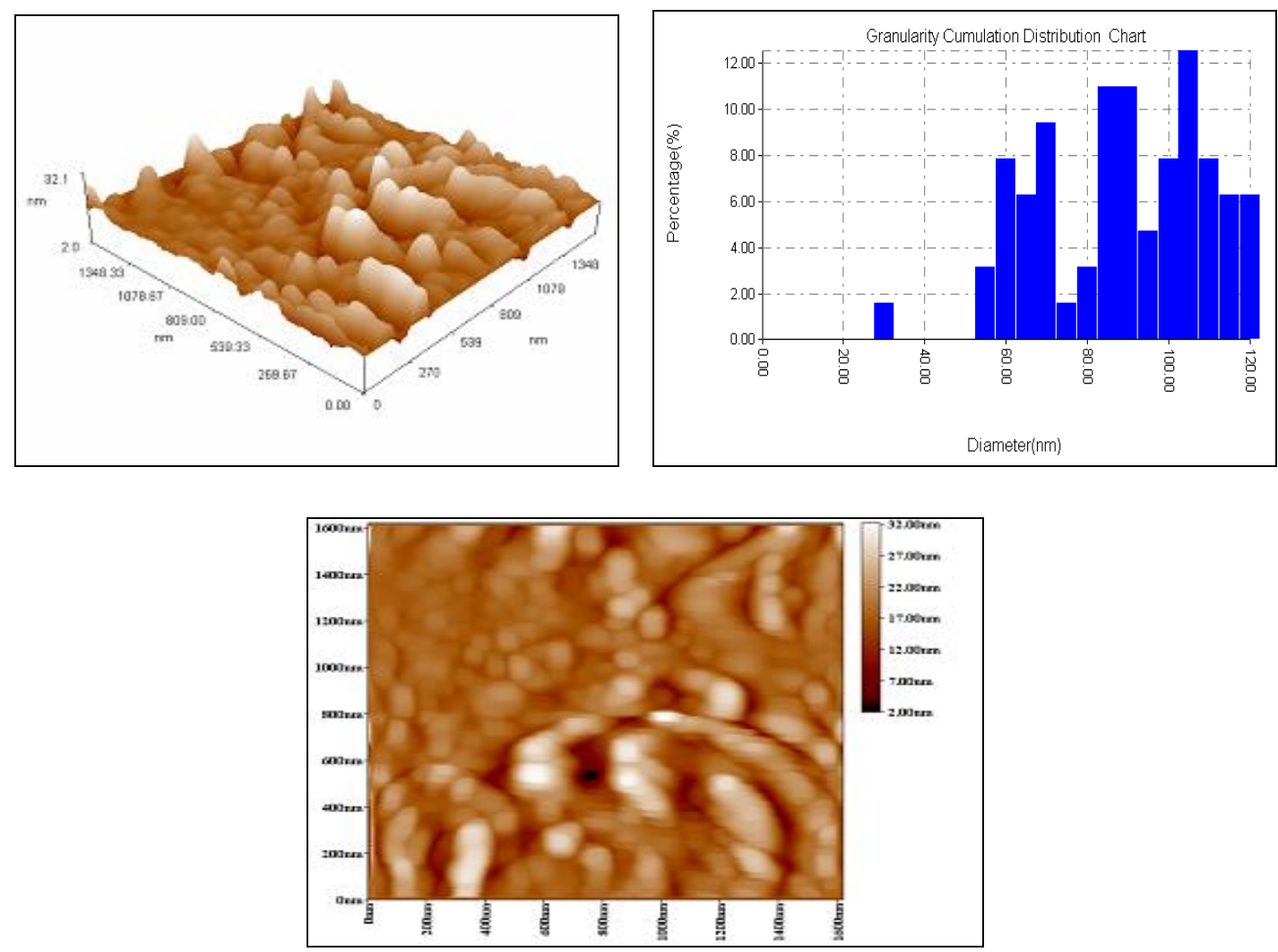

Fig. (4): AFM picture and grain size distribution of phenyl functionalized silica

The results obtained from the thermal analysis were given in Fgure (5). The TGA curve for unfunctionalized silica has one distinct weight-loss region. This occurs in the about $300-400 \mathrm{Co}^{\circ}$ 
range and corresponds to the silanol condensation.[24]

The mass loss observed in the temperature range 200-700 $\mathrm{C}^{\circ}$ for the silica functionalized by methyl group was attributed to the decomposition of methyl group, and correspond to 15
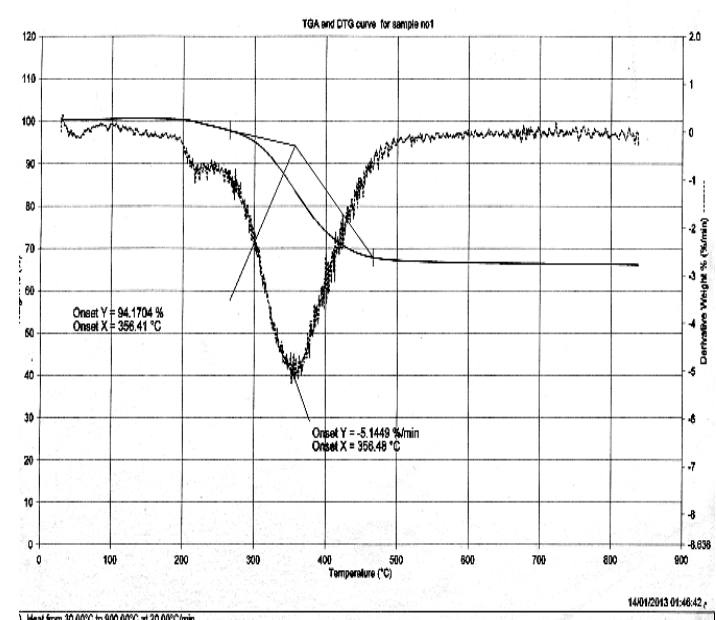

A

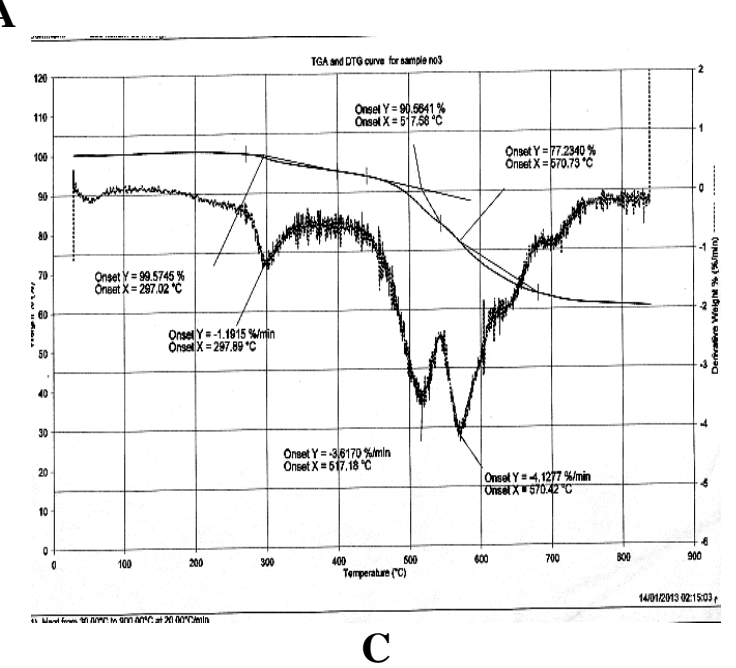

Fig. (5): TGA and DTA curves of (a) Unfunctionalized Silica (b) Methyl Functionalized Silica (c) Phenyl Functionalized Silica

The adsorption isotherms for the three types of silica used in the present work can be considered type IV (see Fig.6) according to the common classification of adsorption isotherms. The hysteresis loops observed are typical for mesoporous materials and resemble the loops of type $\mathrm{H} 1$ according to the IUPAC classification[25,26].

The adsorption isotherms at high relative pressures $(p / p 0>0.2)$ are similar for all materials studied, which mmol of methyl group per gram of silica.

For phenyl functionalized silica, the decomposition of phenyl group was observed in the temperature range 450$700 \mathrm{Co}^{\circ}$ and the mass loss is equal to about $38 \mathrm{mmol}$ of phenyl group per gram silica.

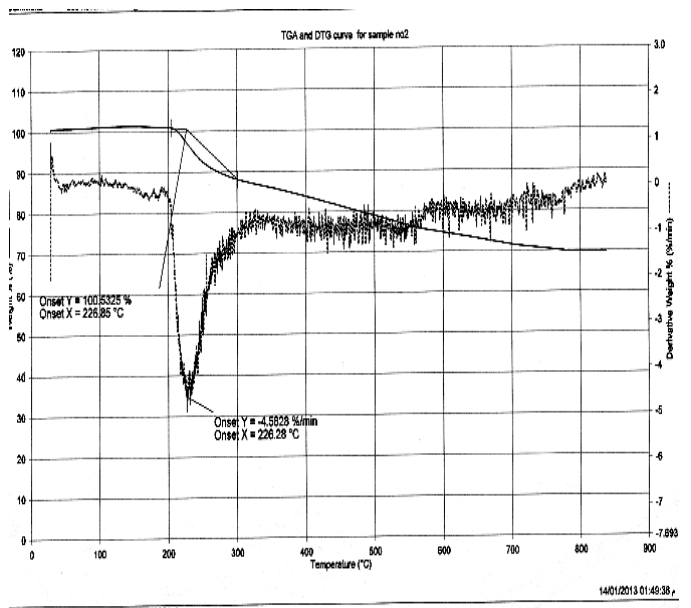

B indicates that no significant changes were introduced in the porous structure of the silica during chemical modification. 

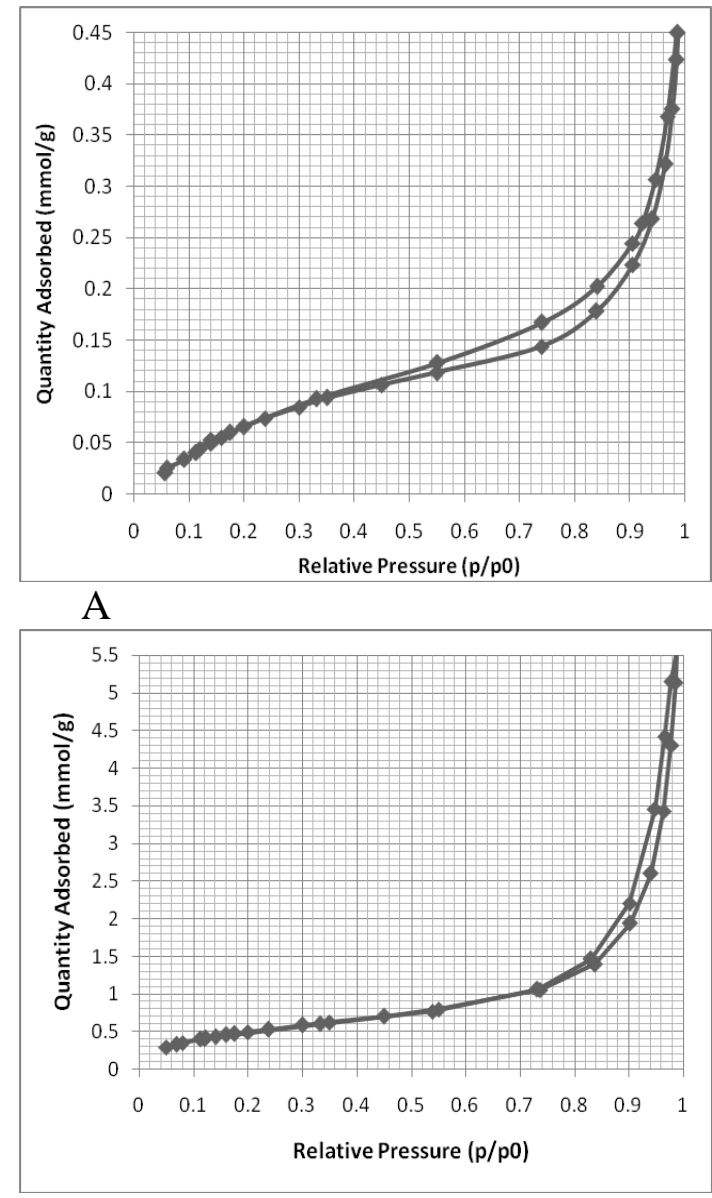

B

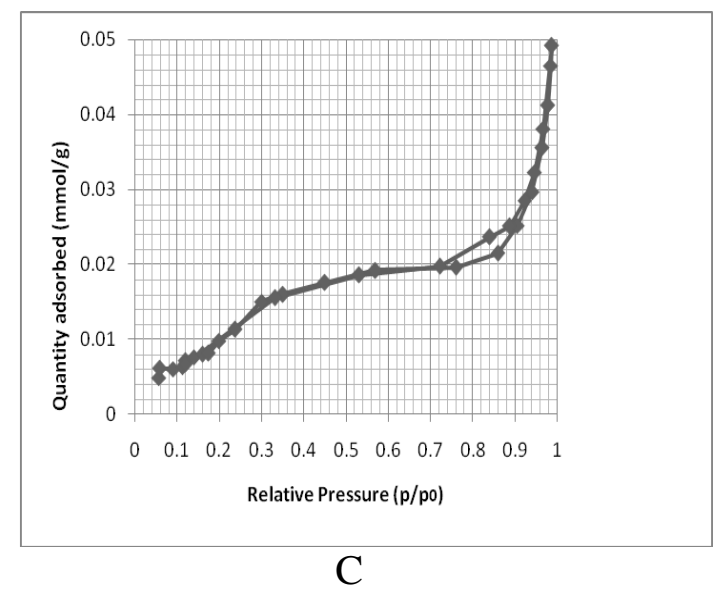

Fig. (6) : $\mathbf{N}_{2}$ Adsorption-desorption isotherms of (a) unfunctionalized silica (b) methyl functionalized silica (c) phenyl functionalized silica

Specific surface areas were calculated following the BET procedure. Pore size distribution was obtained by using the BJH pore analysis applied to the adsorption branch of the nitrogen adsorption/desorption isotherm which relies on the Kelvin equation[27] to relate the width of the pores to the condensation pressure.

The structural properties, specific surface area, pore volume, and $\mathrm{BJH}$ average pore size of the surface of the studied silicas estimated from nitrogen adsorption - desorption are shown in Table (1) .

Table (1): Textural data of the synthesis materials.

\begin{tabular}{|c|c|c|c|}
\hline Materials & $\begin{array}{c}\text { BET } \\
\text { specific } \\
\text { surf. } \\
\text { area } \\
\left(\mathrm{m}^{2} / \mathrm{g}\right)\end{array}$ & $\begin{array}{c}\text { BJH } \\
\text { total pore } \\
\text { vol }\left(\mathrm{cm}^{3} / \mathrm{g}\right)\end{array}$ & $\begin{array}{c}\text { av.Pore } \\
\text { width } \\
(\mathbf{n m})\end{array}$ \\
\hline Silica & $\mathbf{8 . 7 1 6}$ & $\mathbf{0 . 0 1 4 6 9}$ & $\mathbf{6 . 7 1 4 2}$ \\
\hline $\begin{array}{c}\text { Methyl } \\
\text { functionalized } \\
\text { silica }\end{array}$ & 43.463 & $\mathbf{0 . 1 7 8 1 8}$ & 16.398 \\
\hline $\begin{array}{c}\text { Phenyl } \\
\text { functionalized } \\
\text { silica }\end{array}$ & 2.336 & $\mathbf{0 . 0 0 1 6 1}$ & 2.762 \\
\hline
\end{tabular}

As can be seen, the specific surface area, total pore volume expressed per 1 gram of the silica and $\mathrm{BJH}$ average pore size decrease when the silica functionalized with phenyl group but increased when functionalized with methyl group. However, it should be noted that quite significant changes in the structural properties related to the blockage of pores can be observed for the modification of mesoporous with large group.

\section{References:}

[1] Branton PJ, Hall PG, Sing KSW. J Chem Soc Chem Commun 1993; 16:1257-8.

[2] A. Kurganov, K. Unger, T. Issaeva, J. Chromatogr. A 753 (1996) 177.

[3] On DT, Desplantier-Giscard D, Danumah C, Kaliaguine S. Appl Catal A 2001;22:

299-357.

[4] Meynen V, Cool P, Vansant EF. Micropor Mesopor Mater 2009; 125:170-223. 
[5] B. Naik, N.N. Ghosh, Recent Pat. Nanotech. 3 (2009) 213.

[6] T. Benamor, L. Vidal, B. Lebeau, C. Marichal, Micropor. Mesopor. Mater. 153 (2012) 100.

[7] Y.Y. Fahn, Langmuir 21 (2005) 431.

[8] Z.Yun-yu, L. Xao-xuan, C. Zhengxing, "Rapid Synthesis ofwell-ordered mesoporous silica from sodium silicate" Powder Technology, 226 (2012) 239-245.

[9] D.P. Das, K.M. Parida, B.K. Mishra, Journal of Materials Letters 61 (2007) 3942.

[10] S.P. Naik, I. Sokolov, Microporous and Mesoporous Materials 116 (2008) 581.

[11] F.Y. Wei, Z.W. Liu, J. Lu, Z.T. Liu, Microporous and Mesoporous Materials 131

(2010) 224.

[12] T. Foerster, S. Scholz, Y. Zhu, J.A. Lercher, Microporous Mesoporous Mater. 142 (2011) 464-472.

[13] A. Corma, P. Atinzar, H. Garcia, J.Y. Chane-Ching, Nat. Mater. 3 (2004) 394.

[14] X. He, D. Antonelli, Angew. Chem., Int. Ed. 41 (2002) 214.

[15] L. Beaudet, K.Z. Hossain, L. Mercier, Chem. Mater. 15 (2003) 327.

[16] Q. Wei, Z.Q. Nie, Y.L. Hao, Z.X. Chen, W. Wang, J.X. Zou, Mater. Lett. 59 (2005)

3611.

[17] I. Di'az, C. Ma' rquez-Alvarez, F. Mohino, J. Pe' rez-Pariente, E. Sastre, J. Catal. 193 (2000) 283.
[18] J.G. Shen, R.G. Herman, K. Klier, J. Phys. Chem. B 106 (2002) 9975.

[19] X.M. Wang, X.Z. Du, C.L. Li, X. Cao, Appl. Surf. Sci. 254 (2008) 3753.

[20] D. Brandhuber, H. Peterlik, N. $\mathrm{Hu}^{*}$ sing, J. Mater. Chem. 15 (2005) 3896.

[21] J.G. Hou, Q. Ma, X.Z. Du, H.L. Deng, J.Z. Gao, Talanta 62 (2004) 241. [22] X.Z. Du, Y.R. Wang, Q. Ma, X.F. Mao, J.G. Hou, Anal. Lett. 38 (2005) 487.

[23] Q. Huo, D. Margolese, G.D. Stucky, Surfactant control of phases in the synthesis of mesoporous silcabased materials, Chem. Mater. 8 (1996) 1147-1151.

[24] Iler, R. K. The Chemistry of Silica; John Wiley: New York, 1979.

(39.) Riegel, B.; Pittersdorf, S.; Kiefer, W.; Husing, N.; Schubert, U. J. Mol. Structure, 1997, 410-411, 157.

[25] Sing, K. S. W.; Everett, D. H.; Haul, R. A. W.; Moscou, L.; Pierotti,

R. A.; Rouquerol, J.; Siemieniewska, T. Pure Appl. Chem. 1985, 57, 603. [26] Rouquerol, J.; Avnir, D.; Fairbridge, C. W.; Everett, D. H.; Haynes,

J. H.; Pernicone, N.; Ramsay, J. D. F.; Sing, K. S. W.; Unger, K. K. Pure Appl. Chem. 1994, 66, 1739.

[27] E. M. Johanson, 2010, Controlling the Pore Size and Morphology of Mesoporous Silica, Linköping Studies in Science and Technology, Licentiate Thesis No. 1451. 
تحضير وتثخيص وتحليل سطح سيليكا مسامية محورة بأستخدام سيليكات

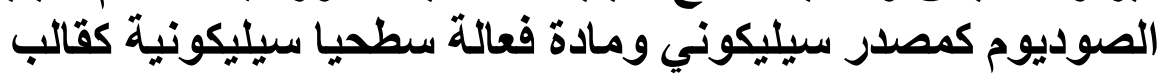

مؤيل كاصد جلهوم***

انعام حسبن علحي*

سمبر حكيب كريبر*

* جامعة بغداد - كلية العلوم للبنات ـ قشم الكيمباء

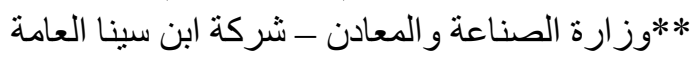

تم تحضير ثلاثة سطو ح لمو اد مسامية سيليكونية محورة وذللك بأدخال مجاميع عضوية مختلفة بأستخدام طريقة

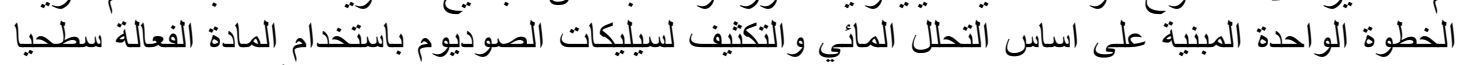

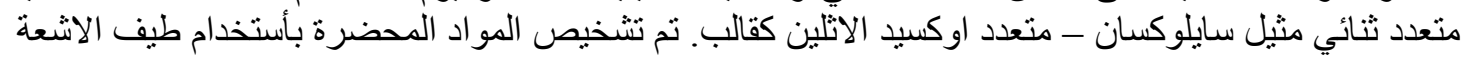

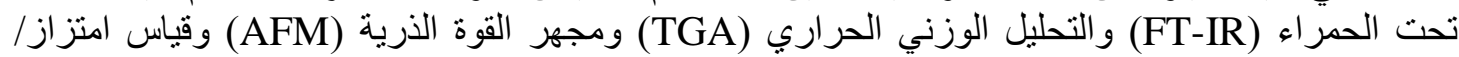

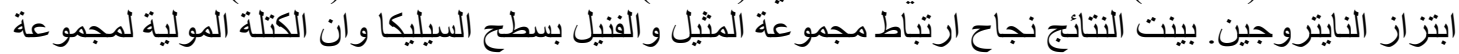

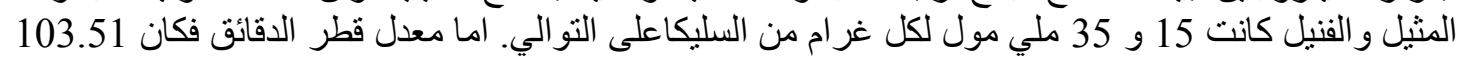

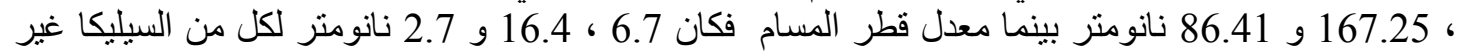

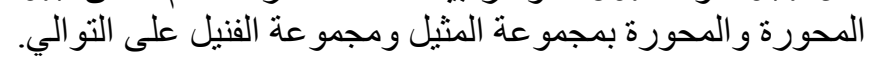

